\title{
Small Wind Turbines Sensorless MPPT: Robustness Analysis and Lossless Approach
}

Andoni Urtasun, Student Member, IEEE, Pablo Sanchis, Senior Member, IEEE, and Luis Marroyo, Member, IEEE

\begin{abstract}
The configuration Permanent Magnet Synchronous Generator (PMSG) with diode bridge is frequently used in small Wind Energy Conversion Systems (WESC) thanks to its reliability and low cost. In order to perform a sensorless Maximum Power Point Tracking (MPPT), a suitable method consists of imposing the relationship between the dc current and the dc voltage in optimum operation. However, this strategy requires having knowledge of the system parameters, which are inaccurately known and can vary in real applications. Thus, optimum curve is not precisely obtained, leading to power losses. This paper evaluates to what extent the power is reduced due to parameter errors. It is shown how the power can be drastically decreased due to some parameter variation whereas it is not affected by others such as the resistance, which can then be neglected in order to simplify the model. Simulation results for an actual wind profile validate the theoretical analysis.
\end{abstract}

Index Terms-Diode bridge, MPPT, PMSG, robustness analysis, sensorless control, variable speed wind generation.

\section{INTRODUCTION}

Wind capacity is growing very quickly thanks to its increasingly competitive prices. During 2012, almost $45 \mathrm{GW}$ began operation and from the end of 2007 through 2012, annual growth rates of cumulative wind power capacity averaged $25 \%$ [1].

Regarding small turbines, more than 21,000 units and $64 \mathrm{MW}$ were installed in 2011 [2]. For small wind generation (typically less than $100 \mathrm{~kW}$ ), a Permanent Magnet Synchronous Generator (PMSG) connected to a diode bridge is preferred because of its reliability, simple control, high efficiency and low cost [3].

Without measuring rotor and wind speeds, two different methods for MPPT are usual with this configuration. The first one is the perturbation and observation technique [4][6]. The problem with this strategy is that larger power variations are often caused by wind changes, which can be misinterpreted by the MPPT strategy. This can drive the system off, resulting in a poor MPPT [7]-[9].

This work was partially funded by the Spanish Ministry of Economy and Competitiveness under Grants DPI2009-14713-C03-01 and DPI201021671-C02-01, by the Government of Navarre and the FEDER funds under project "Microgrids in Navarra: design and implementation" and by the Public University of Navarre.The authors are with Department of Electrical and Electronic Engineering, Public University of Navarra, 31006 Pamplona, Spain (e-mail: andoni.urtasun@unavarra.es; pablo.sanchis@unavarra.es; luisma@unavarra.es).
Another sensorless MPPT method makes the system operate based on a preobtained curve. Normally, the optimum curve $P^{*}(\omega)$ is used [10]-[13]. The problem of this optimum curve is that a shaft speed sensor is required. This is also the case if the curve $V_{d c}{ }^{*}(\omega)$ is used [14].

Some authors have realized that the MPPT can be achieved using only the dc variables. For a certain system, the control imposes the relationship between two dc variables and as a result, the system tracks maximum power [15]-[17]. This technique is adequate for small WECS since it is very simple to implement. However, the optimum curves are complicated to calculate theoretically, especially if losses are considered, since the whole WECS is involved. In fact, in [15] and [16], experimental tests are carried out to obtain the optimum curve. In [17], the authors propose an accurate system modeling which makes it possible to perform a fine MPPT. However, the system parameters, which are required for the optimum curve calculation, are supposed to be perfectly known. In real applications, the parameters have errors and can be variable with temperature or aging. Thus, the MPPT performance will not be as expected and maximum power will not be tracked. Some authors have made a robustness analysis, trying to solve this problem [18], [19]. However, a comprehensive and in-depth study must be carried out.

This paper evaluates the influence of the system parameters on the power captured by the MPPT control. Using the equations and modeling methodology developed in [17], the MPPT efficiency is independently evaluated for the different parameters. Then, it is shown how the power is significantly reduced for two negative but realistic scenarios of parameter variation. Finally, the influence of the resistance is also assessed. Although the resistance makes change the power curves, it is proved that it can be neglected for the optimum curve calculation with no power reduction, which makes this calculation much easier.

\section{MODELING OF THE WHOLE SySTEM}

The WECS analyzed in this work is shown in Fig. 1, where $v_{w}$ is the wind speed, $\omega_{m}$ is the mechanical speed, $V_{d c}$ is the diode bridge output voltage, $I_{L}$ is the inductor current, $C_{d c}$ represents the capacitor at the diode bridge output, and $L_{d c}$ represents the inductor of the boost converter. The power balance of the system at steady-state is as follows. $P_{T}$ is the power captured by the wind turbine once the friction losses have been deducted. It depends on wind speed $v_{w}$ and mechanical speed $\omega_{m}$, that is $P_{T}\left(v_{w}, \omega_{m}\right)$, and is equal to the 
PMSG electromagnetic power $P_{e m}\left(\omega_{m}, V_{d c}\right)$. Neglecting the magnetic losses of the machine and the diode losses of the bridge, the electromagnetic power $P_{e m}\left(\omega_{m}, V_{d c}\right)$ is split into the resistive losses caused by the PMSG and the line, $P_{R}\left(\omega_{m}, V_{d c}\right)$, and the diode bridge output power, $P_{0}\left(\omega_{m}, V_{d c}\right)$. Finally, $P_{0}\left(\omega_{m}, V_{d c}\right)$ is equal to the input power of the boost converter, $P_{L}\left(V_{d c}, I_{L}\right)=V_{d c} \cdot I_{L}$.

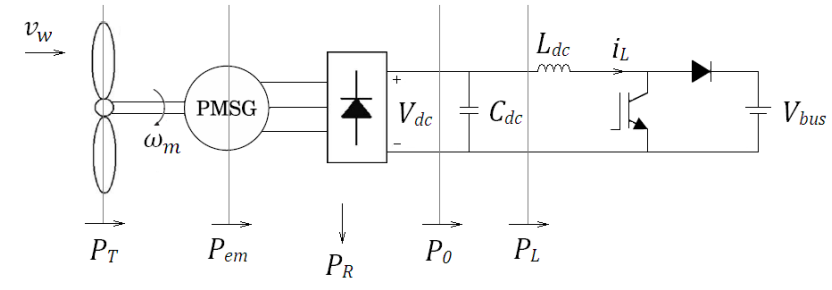

Figure 1. Global system and power balance

In this paper, the whole WECS model which was developed and experimentally validated in [17] is used to calculate the optimum curve $I_{\text {Lopt }}\left(V_{d c}\right)$. Then, this curve is stored and, in operation, the boost converter controls $I_{L}$ in such a way that the curve is always imposed. For this purpose, dc voltage is measured and inductor current reference is obtained from $I_{L o p t}\left(V_{d c}\right)$. The same model is also employed in order to evaluate the robustness of the control against parameter variation. The features of the wind turbine and the specifications of the PMSG and the line used throughout this paper are compiled in Table I and Table II, respectively.

TABLE I. Features of THE Wind TURBine Placed IN THE CAMPus of THE Public University of NAVARRa (PAMPlona, SPAin)

\begin{tabular}{|c|c|}
\hline Nominal power & $4200 \mathrm{~W}$ \\
\hline Wind speed for turn on & $3.5 \mathrm{~m} / \mathrm{s}$ \\
\hline Wind speed for nominal power & $12 \mathrm{~m} / \mathrm{s}$ \\
\hline Optimum power coefficient & 0.316 \\
\hline Optimum tip speed ratio & 8.63 \\
\hline Diameter of the rotor & $4 \mathrm{~m}$ \\
\hline Inertia & $5 \mathrm{~kg} \cdot \mathrm{m}^{2}$ \\
\hline Height of the nacelle & $23 \mathrm{~m}$ \\
\hline
\end{tabular}

TABLE II. SPECIFICATIONS OF THE PMSG AND THE LiNE

\begin{tabular}{|c|c|}
\hline Nominal speed & $600 \mathrm{rpm}$ \\
\hline Line voltage constant & $475 \mathrm{~V} / \mathrm{krpm}$ \\
\hline Nominal current & $11.6 \mathrm{~A}$ \\
\hline Number of pole pairs & 15 pairs \\
\hline Stator equivalent resistance & $0.6 \Omega$ \\
\hline Stator equivalent inductance & $4.9 \mathrm{mH}$ \\
\hline Line resistance & $0.2 \Omega$ \\
\hline Line inductance & $0.3 \mathrm{mH}$ \\
\hline
\end{tabular}

\section{OPTIMUM CURVE CALCULATION}

The power captured by a wind turbine $P_{T}$ depends on wind and turbine speeds. Curves of $P_{T}$ at a constant wind speed $(6 \mathrm{~m} / \mathrm{s}, 8 \mathrm{~m} / \mathrm{s}, 10 \mathrm{~m} / \mathrm{s}$ and $12 \mathrm{~m} / \mathrm{s})$ are represented in Fig. 2. For each wind speed, there is a certain turbine speed which maximizes the captured power. Thus, an optimum curve $P_{\text {Topt }}\left(\omega_{m}\right)$ can be obtained, which is usually provided by the turbine manufacturer. For instance, for a wind speed $v_{w A}=10 \mathrm{~m} / \mathrm{s}$, the optimum power is $P_{\text {ToptA }}=2429 \mathrm{~W}$ and it is extracted for a rotor speed $\omega_{m A}=412 \mathrm{rpm}$ (see Fig. 2 and operating point A). On the other hand, electromagnetic power $P_{e m}$ depends on turbine speed and dc voltage. It is also plotted in Fig. 2 at a constant voltage $(150 \mathrm{~V}, 218 \mathrm{~V}$ and $300 \mathrm{~V})$. Since captured power $P_{T}$ is equal to electromagnetic power $P_{e m}$ at steady-state, the system will operate in the intersection of both curves, which yields to $V_{d c A}=218 \mathrm{~V}$ for point A. Once $\omega_{m A}$ and $V_{d c A}$ are known, the power losses for point A can be worked out and $P_{0}$ can be calculated, $P_{0 A}=2272 \mathrm{~W}$ in this case. Finally, $\mathrm{I}_{\mathrm{L}}$ can be easily obtained as $I_{L A}=P_{O A} / V_{d c A}=10.42 \mathrm{~A}$. Thus, proceeding similarly for all points, optimum curves $P_{0 o p t}\left(\omega_{m}\right)$ and its corresponding $I_{\text {Lopt }}\left(V_{d c}\right)$ can be obtained and are shown in Fig. 2 and Fig. 3, respectively.

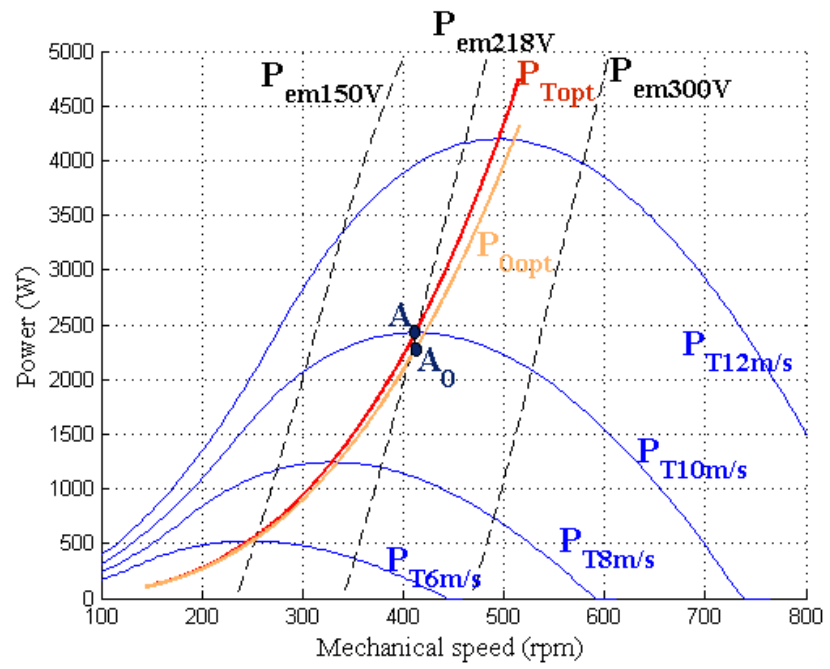

Figure 2. Wind turbine curves, electromagnetic power curves and optimum curves $P_{\text {Topt }}$ and $P_{0 o p t}$ versus $\omega_{m}$

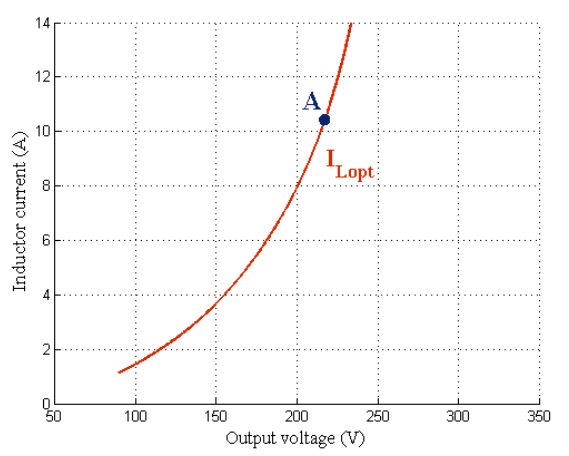

Figure 3. Optimum curve $I_{\text {Lopt }}$ versus $V_{d c}$

\section{RoBUSTNESS ANALYSIS}

The MPPT technique previously described will be employed in this paper. For the calculation of the optimum curve the system parameters are required. These parameters include the features of the PMSG and the line (PMSG 
voltage constant $k$, resistance of the PMSG and the line $R$, and inductance of the PMSG and the line $L$ ) and the features of the wind turbine optimum curve $P_{\text {Topt }}\left(\omega_{m}\right)\left(C_{\text {popt }}\right.$ and $\left.\lambda_{\text {opt }}\right)$.

If the real system parameters were equal to the parameters used for the optimum curve calculation, to be called $k_{\text {calc }}, R_{\text {calc }}, L_{\text {calc }}$, $\left(\lambda_{\text {opt }}\right)_{\text {calc }}$ and $\left(C_{\text {popt }}\right)_{\text {calc }}$, the MPPT efficiency would be $100 \%$ at steady-state. However, in a real system, parameters are not usually accurately known and can be variable with many factors such as temperature and aging. Accordingly, the parameters considered differ from its real values and the calculated optimum curve $I_{L c a l c}\left(V_{d c}\right)$ is not equal to the actual optimum curve $I_{\text {Lopt }}\left(V_{d c}\right)$. As a result, turbine speed is different to optimum speed $\omega_{\text {mopt }}$ for a certain wind speed and the power captured by the turbine is lower than the optimum power $P_{\text {Topt }}$.

Accounting for the characteristics of the different elements, the following variation range will be considered for the system parameters:

- Voltage constant of the PMSG $k$ is generally well given by the manufacturer but can vary due to saturation: $\pm 10 \%$ range is considered.

- Equivalent resistance $R$ and inductance $L$ of the PMSG and the line can be imprecisely known and change with the temperature: $\pm 30 \%$ range.

- Optimum curve $P_{\text {Topt }}\left(\omega_{m}\right)$ can also be inaccurately provided by the manufacturer. $\pm 20 \%$ range will be considered for $\lambda_{\text {opt }}$ and $C_{\text {Popt }}$.

With the model developed in [17], the power reduction can be predicted. In section A, the MPPT efficiency for each parameter variation will be independently studied. Then, in section B, the two worst scenarios will be described. Finally, in section $\mathrm{C}$, the MPPT efficiency for a model with $R=0$ will be analyzed.

\section{A. Single Parameter Variation}

If the optimum power coefficient given by the manufacturer $\left(C_{P o p t}\right)_{c a l c}$ is a $20 \%$ higher than its real value, that is $\left(C_{P o p t}\right)_{\text {calc }}=1.2 \cdot C_{\text {Popt }}$, curve $I_{L C p+}\left(V_{d c}\right)$, represented in Fig. 5, will be worked as the optimum curve but in reality differs from the actual optimum curve $I_{\text {Lopt }}\left(V_{d c}\right)$. By means of the model of [17] and using now the real parameter $C_{P o p t}$, $I_{L C p+}\left(V_{d c}\right)$ can be translated to $P_{T C p+}\left(\omega_{m}\right)$, shown in Fig. 4, which is different to the actual optimum curve $P_{\text {Topt }}\left(\omega_{m}\right)$. This means that the intersection of the curve $P_{T C p+}\left(\omega_{m}\right)$ with the turbine power curve $P_{T}\left(v_{w}, \omega_{m}\right)$ will not lead to the maximum power for any wind speed. For example, for a wind speed $v_{w B}=10 \mathrm{~m} / \mathrm{s}, P_{T B}=2411 \mathrm{~W}$, whereas the maximum power is $P_{T A}=2429 \mathrm{~W}$, which yields to a MPPT efficiency $\eta_{B}=99.26 \%$ (see point $\mathrm{B}$ in the figures). The MPPT efficiency at steady-state $\eta_{C p+}\left(v_{w}\right)$ is shown in Fig. 6 for every wind speed. Now, if the optimum power coefficient given by the manufacturer $\left(C_{\text {Popt }}\right)_{\text {calc }}$ is a $20 \%$ lower than its real value, that is $\left(C_{\text {Popt }}\right)_{\text {calc }}=C_{\text {Popt }} / 1.2$, the power is also reduced. The power curve $P_{T C p}\left(\omega_{m}\right)$, inductor current curve $I_{L C p-}\left(V_{d c}\right)$ and the efficiency curve $\eta_{C p}\left(v_{w}\right)$ are shown in
Fig. 4, 5 and 6, respectively. It can be observed that $C_{P o p t}$ variation effect is low since the MPPT efficiency is higher than $99.2 \%$ for the whole operating range.

The same analysis has been independently carried out for all the parameters. For the optimum tip speed ratio $\lambda_{\text {opt }}$, the corresponding power curves $P_{T \lambda+}\left(\omega_{m}\right)$ and $P_{T \lambda-}\left(\omega_{m}\right)$, inductor current curves $I_{L \lambda+}\left(V_{d c}\right)$ and $I_{L \lambda-}\left(V_{d c}\right)$ and efficiency curves $\eta_{\lambda+}\left(v_{w}\right)$ and $\eta_{\lambda-}\left(v_{w}\right)$, are represented in Fig. 4, 5 and 9, respectively.

With regard to the electrical parameters, the power curves $P_{T k+}\left(\omega_{m}\right), P_{T k-}\left(\omega_{m}\right), P_{T L_{+}}\left(\omega_{m}\right), P_{T L-}\left(\omega_{m}\right), P_{T R+}\left(\omega_{m}\right)$ and $P_{T R-}\left(\omega_{m}\right)$ are depicted in Fig. 7 and the inductor current curves $I_{L k+}\left(V_{d c}\right), I_{L k-}\left(V_{d c}\right), I_{L L+}\left(V_{d c}\right), I_{L L-}\left(V_{d c}\right), I_{L R+}\left(V_{d c}\right)$ and $I_{L R-}$ $\left(V_{d c}\right)$ are depicted in Fig. 8. The MPPT efficiency curves $\eta_{k+}\left(v_{w}\right)$ and $\eta_{k-}\left(v_{w}\right)$ are represented in Fig. 9 and $\eta_{L+}\left(v_{w}\right)$, $\eta_{L-}\left(v_{w}\right), \eta_{R+}\left(v_{w}\right)$ and $\eta_{R-}\left(v_{w}\right)$ are shown in Fig. 6.

From the MPPT efficiency at steady-state for all the parameters (see Fig. 6 and 9), it can be observed that $\lambda_{\text {opt }}$ is the most influential, followed by $k, C_{P}, L$ and finally $R$. The effect of $C_{P}, L$ and $R$ is not important for the considered range, the parameter $k$ starts to be significant and the effect of parameter $\lambda_{\text {opt }}$ is important. Since more energy is captured at high wind speeds, it must be noted that these operating points are more significant.

\section{B. Worst scenarios}

It was shown for $C_{\text {popt }}$ (see Fig. 4), that when $\left(C_{\text {popt }}\right)_{\text {calc }}>C_{\text {popt }}$, the system operates at a speed lower that the optimum speed. On the contrary, when $\left(C_{\text {popt }}\right)_{\text {calc }}<C_{\text {popt }}$, the system operates at higher speed. After evaluating the effect of each parameter variation, the two worst scenarios can be analyzed. The first one, denoted by $\omega_{\max }$, consists of a combination of parameter variation in such a way that all parameters contribute towards an operating point with a speed higher than the real optimum speed. Accounting for the considered variation range and the effect of each parameter, the worst scenario $\omega_{\max }$ is found for: $k_{\text {calc }}=1.1 \cdot k$, $R_{\text {calc }}=R / 1.3, \quad L_{\text {calc }}=L / 1.3, \quad\left(\lambda_{\text {opt }}\right)_{\text {calc }}=1.2 \cdot \lambda_{\text {opt }} \quad$ and $\left(C_{\text {popt }}\right)_{\text {calc }}=C_{\text {popt }} / 1.2$. In this case, the calculated optimum curve is $I_{\text {Lomax }}\left(V_{d c}\right)$, shown in Fig. 11, which leads to a captured power $P_{\text {Twmax }}\left(\omega_{m}\right)$, represented in Fig. 10 . The MPPT efficiency $\eta_{\omega \max }\left(v_{w}\right)$ is significantly reduced, as it can be observed in Fig. 12. Point D, also shown in the figures, corresponds to the real operating point for $v_{w D}=10 \mathrm{~m} / \mathrm{s}$. On the other hand, the worst scenario $\omega_{\min }$ is found for: $k_{\text {calc }}=k / 1.1, R_{\text {calc }}=1.3 \cdot R, L_{\text {calc }}=1.3 \cdot L,\left(\lambda_{\text {opt }}\right)_{\text {calc }}=\lambda_{\text {opt }} / 1.2$ and $\left(C_{\text {popt }}\right)_{\text {calc }}=1.2 \cdot C_{\text {popt }}$. The calculated optimum curve $I_{L \omega m i n}\left(V_{d c}\right)$ is plotted in Fig. 11 and the captured power $P_{\text {Twmin }}\left(\omega_{m}\right)$ is depicted in Fig. 10. The MPPT efficiency $\eta_{\text {wmin }}\left(v_{w}\right)$, shown in Fig. 12 , is drastically reduced. Point C, also represented in the figures, corresponds to the real operating point for $v_{w C}=10 \mathrm{~m} / \mathrm{s}$.

In addition, maximum values must be taken into account. For the worst situation $\omega_{\max }$, rotor speed $\omega_{m}$ and output voltage $V_{d c}$ can exceed the nominal values. In our example, for nominal wind speed $v_{w}=12 \mathrm{~m} / \mathrm{s}$, rotor speed becomes $664 \mathrm{rpm}$ and output voltage becomes $368 \mathrm{~V}$ while optimum 


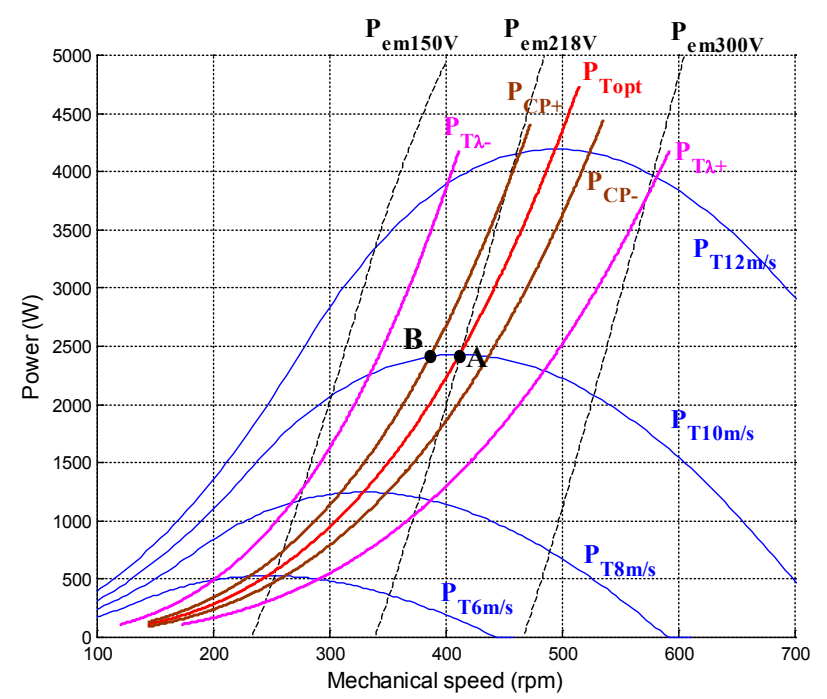

Figure 4. Wind turbine curves, electromagnetic power curves and calculated optimum power curves $P_{T \lambda}$ and $P_{T C P}$ versus $\omega_{m}$

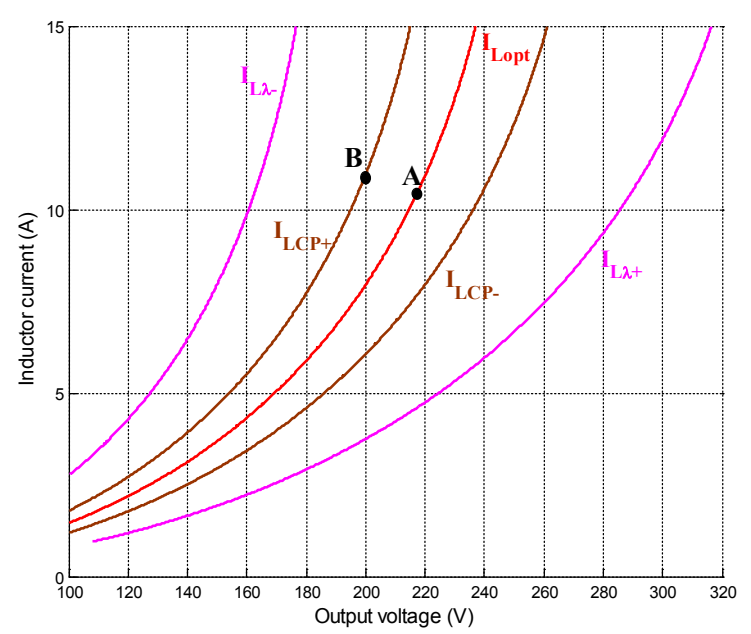

Figure 5. Calculated optimum current curves $I_{L \lambda}$ and $I_{L C P}$ versus $V_{d c}$

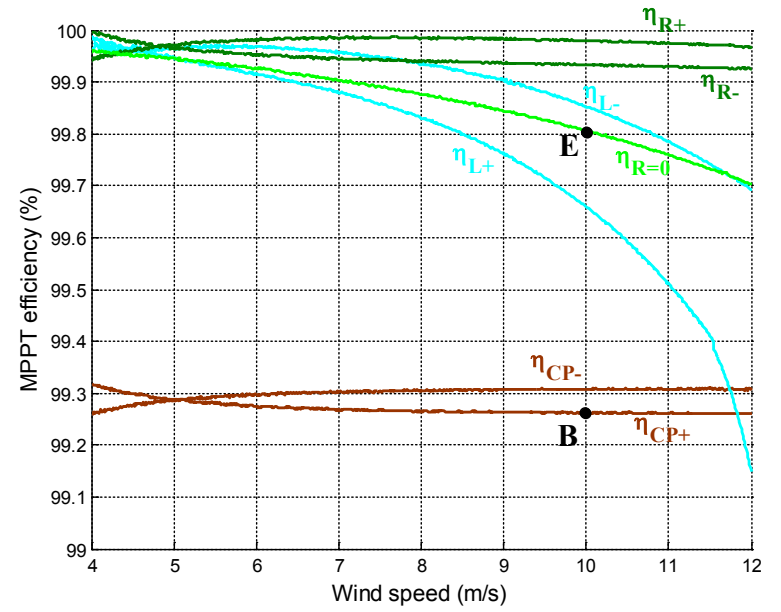

Figure 6. MPPT efficiency at steady-state $\eta_{R}, \eta_{R=0}, \eta_{L}$ and $\eta_{C P}$ versus $v_{w}$

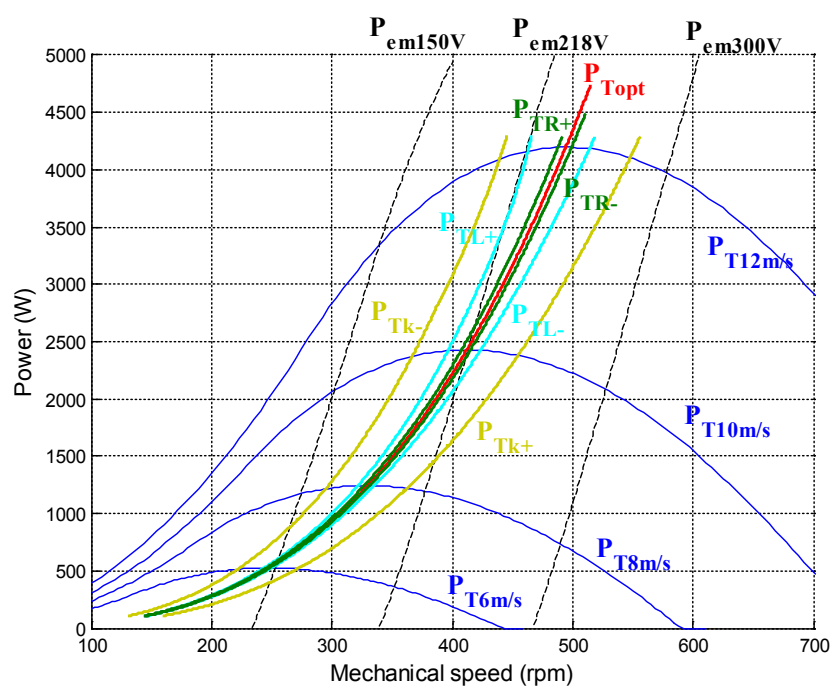

Figure 7. Wind turbine curves, electromagnetic power curves and calculated optimum power curves $P_{T k}, P_{T L}$ and $P_{T R}$ versus $\omega_{m}$

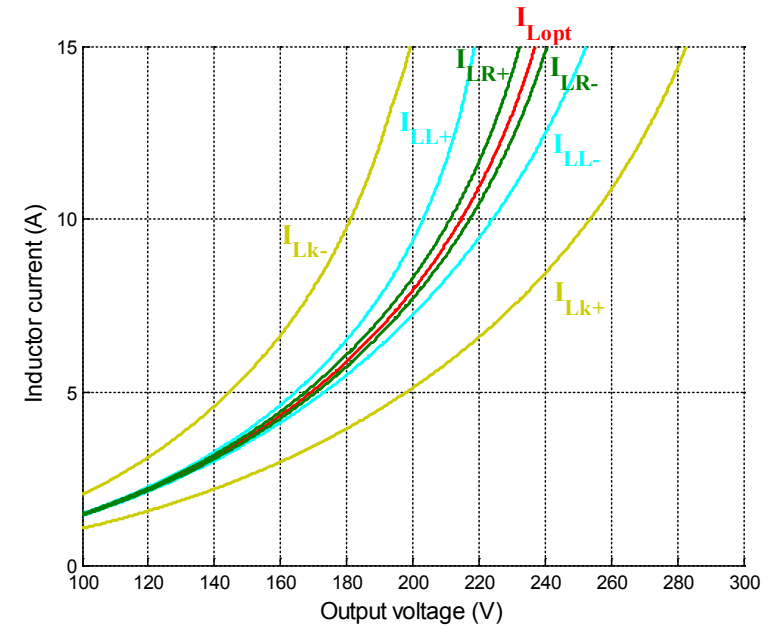

Figure 8. Calculated optimum current curves $I_{L k}, I_{L L}$ and $I_{L R}$ versus $V_{d c}$

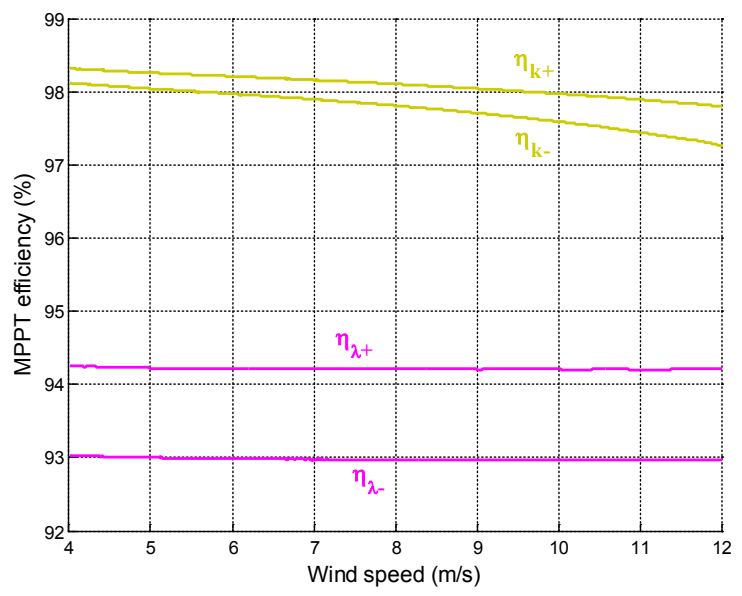

Figure 9. MPPT efficiency at steady-state $\eta_{\lambda}$ and $\eta_{k}$ versus $v_{w}$ 


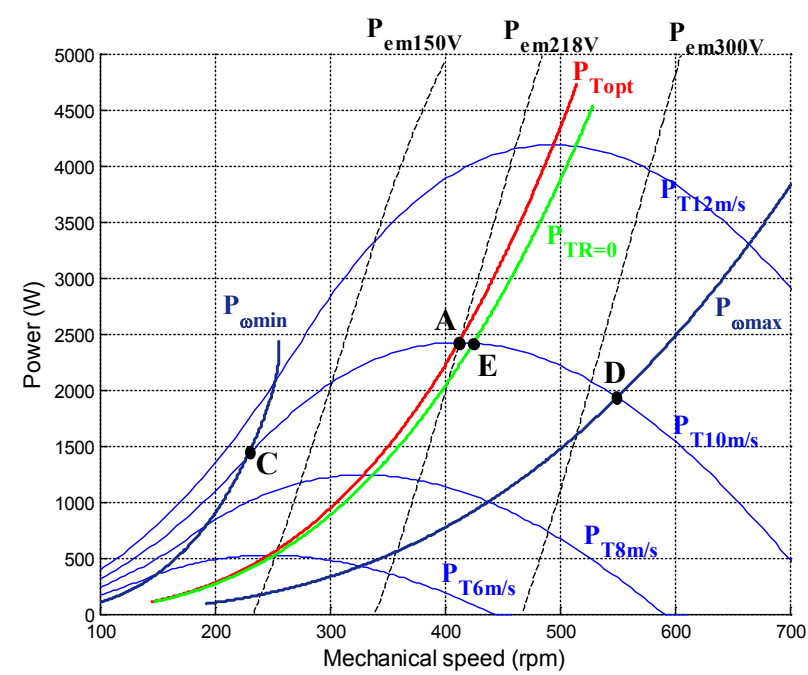

Figure 10. Wind turbine curves, electromagnetic power curves and calculated optimum power curves $P_{\omega \min }, P_{\omega \max }$ and $P_{R=0}$ versus $\omega_{m}$

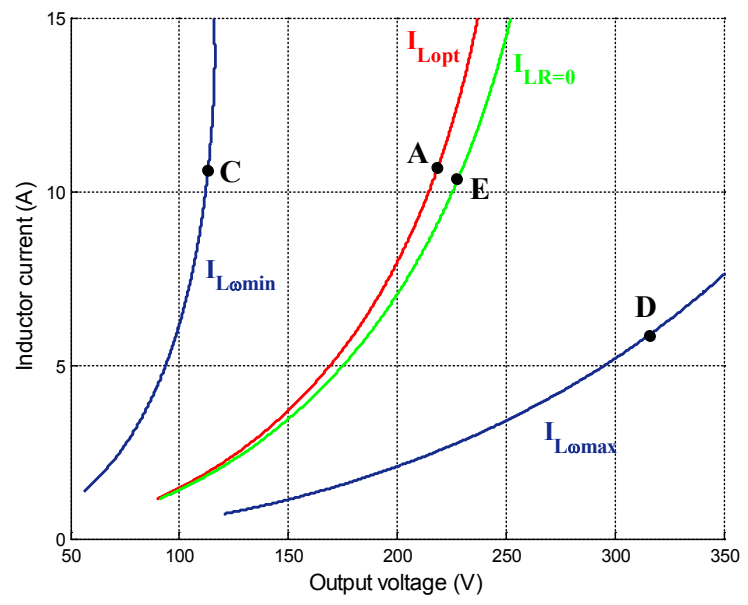

Figure 11. Calculated optimum current curves $I_{L \omega m i n}, I_{L \omega m a x}$ and $I_{L R=0}$ versus $V_{d c}$

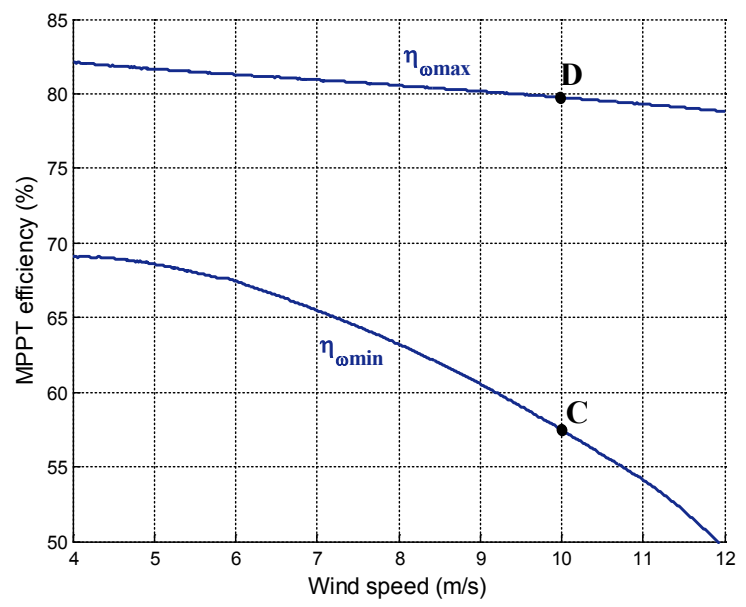

Figure 12. MPPT efficiency at steady-state $\eta_{\omega \min }$ and $\eta_{\omega \max }$ versus $v_{w}$ values are $495 \mathrm{rpm}$ and $240 \mathrm{~V}$. For the worst situation $\omega_{\min }$, it is inductor current $I_{L}$ that can exceed nominal current. This is not the case in this example, but attention must be paid. Furthermore, the system operates with low voltages and high currents, which reduces the overall efficiency.

\section{Lossless Approach}

It has been shown (see Fig. 6), that the resistance's effect is very small. More precisely, the power reduction for the variation range considered is lower than $0.1 \%$.

For this reason, the same robustness analysis has been carried out neglecting the losses, that is for $R_{\text {calc }}=0$. The corresponding power curve $P_{T R=0}\left(\omega_{m}\right)$, inductor current curve $I_{L R=0}\left(V_{d c}\right)$ and efficiency curve $\eta_{R=0}\left(v_{w}\right)$ are represented in Fig. 10, 11 and 6, respectively. Point E, pointed out in the figures, corresponds to the real operating point for $v_{w E}=10 \mathrm{~m} / \mathrm{s}$.

From the MPPT efficiency $\eta_{R=0}\left(v_{w}\right)$, it can be observed that the effect of considering $R=0$ is very small. In fact, the MPPT efficiency is higher than $99.7 \%$ for every operating point. As a result, the resistance can be neglected for the optimum curve calculation, which strongly simplifies the modeling. It is worth mentioning that the variation of other parameters will reduce the captured power in a very similar manner to the precedent analysis. The modeling of the subsystem PMSG with diode bridge with $R=0$ is developed in the next section following the methodology of [17].

\section{MOdELING OF THE PMSG WITH DIODE BRIDGE FOR THE LOSSLESS APPROACH}

\section{A. System Description}

The equivalent circuit of a PMSG connected to a diode bridge at steady-state operation is shown in Fig. 13, where $R$ and $L$ include the resistance and inductance of the PMSG, the line, and the possible transformer; $e_{a}, e_{b}$ and $e_{c}$ are the induced electromotive forces; $i_{a}, i_{b}$ and $i_{c}$ are the phase currents; $i_{d c}$ is the diode bridge output current; and $V_{d c}$ is the diode bridge output voltage. Since the losses are neglected, $R$ is taken as 0 for the subsequent analysis.

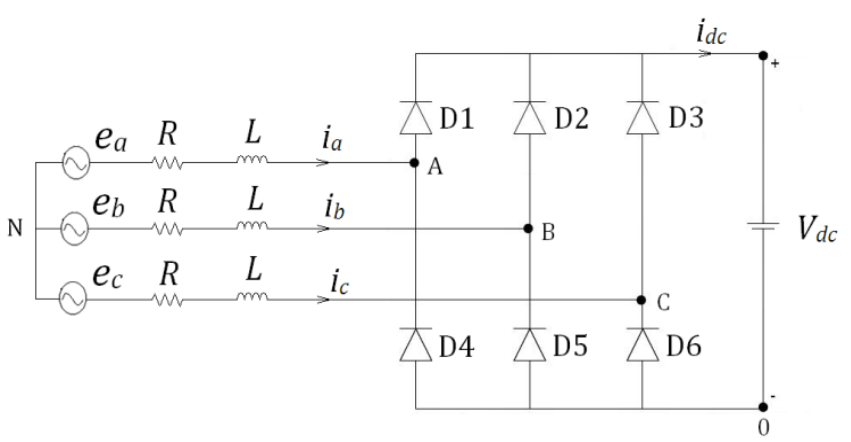

Figure 13. Equivalent circuit of a PMSG connected to a diode bridge at steady-state ( $R$ is neglected)

The electrical system, represented by Fig. 13, is related to the mechanical system by: 


$$
\begin{gathered}
e_{a}=\sqrt{2} E \sin (\theta) \\
e_{b}=\sqrt{2} E \sin (\theta-2 \pi / 3) \\
e_{c}=\sqrt{2} E \sin (\theta+2 \pi / 3) \\
E=k \cdot \omega \\
\theta=\omega \cdot t \\
\omega=p \cdot \omega_{m}
\end{gathered}
$$

where $E$ is the RMS value of the induced electromotive force, $\theta$ is the electrical angle, $k$ is the PMSG voltage constant, $\omega$ is the electrical speed, $p$ is the number of pole pairs, and $\omega_{m}$ is the mechanical speed.

Operating at steady-state and given that the $C_{d c}$ capacitor and the system inertia are high enough to neglect the ripple, the voltage $V_{d c}$ and the speeds $\omega$ and $\omega_{m}$ can be considered as constant. Depending on the value of $\omega_{m}$ and $V_{d c}$, the phase current will be either continuous or discontinuous, resulting in different expressions for powers. Since the system is balanced, only phase A is henceforth studied.

\section{B. Continuous Conduction Mode (CCM)}

For high voltage $E$ or low voltage $V_{d c}$ the current is continuous (the exact relationship for the boundary will be obtained in section V.D). Thus, each diode conducts for $\pi$ radians: D1 while the current of phase A is positive and D4 while it is negative. Fig. 14 shows voltages $e_{a}$ and $v_{A N}$, currents $i_{a}, i_{b}, i_{c}$ and $i_{d c}$ and the lag angle $\varphi$ between $e_{a}$ and $i_{a}$. According to the commutations, six intervals (I1-I6) are defined in a period.
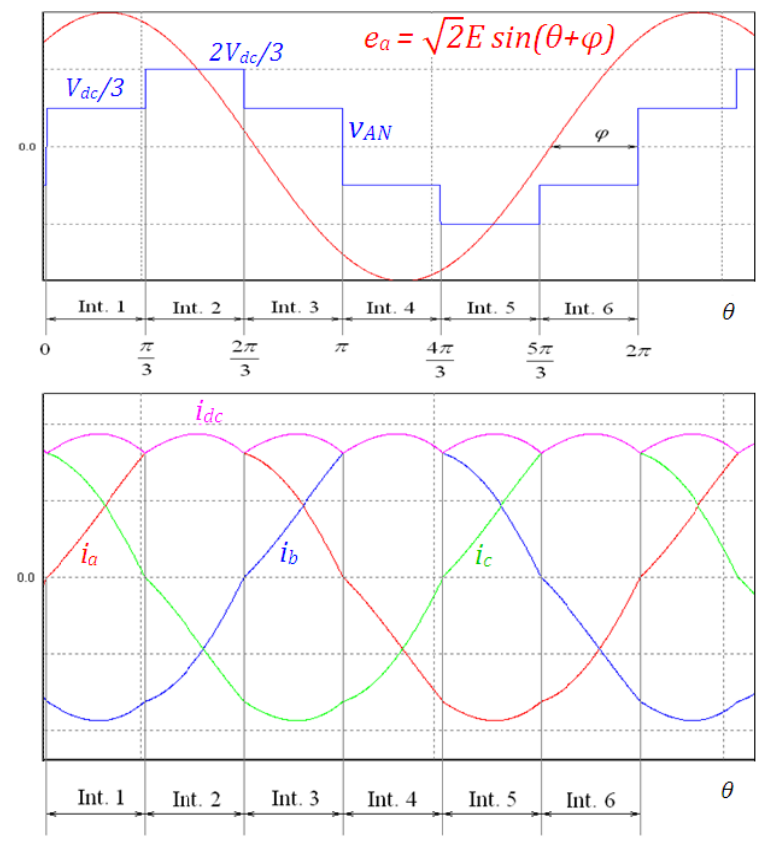

Figure 14. Waves for continuous conduction mode (CCM)
The current $i_{a}$ can be obtained from the following differential equation:

$$
\begin{gathered}
\omega L \frac{d i_{a}}{d \theta}=e_{a}-v_{A N}, \quad i_{a}(\theta=0)=0 \\
I 1: i_{a}(\theta)=\frac{\sqrt{2} k}{L}[\cos \varphi-\cos (\theta+\varphi)]-\frac{V_{d c}}{3 \omega L} \cdot \theta \\
I 2: i_{a}(\theta)=\frac{\sqrt{2} k}{L}[\cos \varphi-\cos (\theta+\varphi)]-\frac{V_{d c}}{3 \omega L}\left(2 \theta-\frac{\pi}{3}\right) \\
I 3: i_{a}(\theta)=\frac{\sqrt{2} k}{L}[\cos \varphi-\cos (\theta+\varphi)]-\frac{V_{d c}}{3 \omega L}\left(\theta+\frac{\pi}{3}\right)
\end{gathered}
$$

Then, thanks to the condition $i_{a}(\theta=\pi)=0$ (see Fig. 14) and (10), the angle $\varphi$ can be calculated:

$$
\varphi=\cos ^{-1}\left(\frac{\sqrt{2} \pi \cdot V_{d c}}{9 E}\right)
$$

On account of expressions (8)-(11), $i_{a}$ is now defined at any time as a function of the shaft speed $\omega_{m}$ and the capacitor voltage $V_{d c}$ at steady-state operation.

Since the losses are neglected for the modeling, the PMSG electromagnetic power $P_{e m}$ is equal to the power at the diode bridge output $P_{0}$. In order to work this power out, it must be observed that the current $i_{a}$ coincides with the output current $i_{d c}$ in interval 2, where D1 is conducting and D2 and D3 are switched off (see Fig. 14). The ripple of $i_{d c}$ has a $6 \omega$ angular frequency. Thus, the output power $P_{0}$ is given by:

$$
P_{0}=V_{d c} \cdot I_{d c}=V_{d c} \cdot \frac{3}{\pi} \cdot \int_{\frac{\pi}{3}}^{\frac{2 \pi}{3}} i_{a}(\theta) d \theta
$$

where $I_{d c}$ is the average value of $i_{d c}$.

Using (12) and the expression for the current $i_{a}(9)$, an expression for the diode bridge output power $P_{0}\left(\omega_{m}, V_{d c}\right)$ in CCM is obtained as a function of the shaft speed $\omega_{m}$ and the capacitor voltage $V_{d c}$ :

$$
P_{0}=\frac{3 \sqrt{2} k \cdot V_{d c}}{\pi L} \sin \varphi=\frac{V_{d c}}{3 \pi \omega L} \sqrt{162 E^{2}-4 \pi^{2} V_{d c}^{2}}
$$

\section{Discontinuous Conduction Mode (DCM)}

For low voltage $E$ or high voltage $V_{d c}$ the current is discontinuous (the exact relationship for the boundary will be obtained in section V.D). There is a retard angle $\alpha$ for each diode during which the current is zero in one of the phases. Because of the discontinuous conduction, and contrary to the three intervals defined in CCM, six intervals (I1-I6) are identified in a semi-period. The evolution of $v_{A N}$ and the six intervals are shown in Fig. 15. The voltage $e_{a}$ and currents $i_{a}$, $i_{b}, i_{c}$ and $i_{d c}$ are also illustrated. Although three cases of DCM can be distinguished [20], only the case which is closer to the $\mathrm{CCM}$ is analyzed for the purposes of this paper. 
The current $i_{a}$ in DCM can also be obtained from (7) but taking into account that $v_{A N}$ in DCM is different to $v_{A N}$ in CCM (compare Fig. 14 and Fig. 15):

$$
\text { I1: } i_{a}(\theta)=0
$$

$I 2: i_{a}(\theta)=\frac{\sqrt{2} k}{L}[\cos (\alpha+\varphi)-\cos (\theta+\varphi)]-\frac{V_{d c}}{3 \omega L}(\theta-\alpha)($

$$
\begin{aligned}
I 3: i_{a}(\theta)=\frac{\sqrt{2} k}{2 L}[ & \left.2 \cos (\alpha+\varphi)-\cos \varphi-\sqrt{3} \cos \left(\theta+\varphi+\frac{\pi}{6}\right)\right]- \\
& -\frac{V_{d c}}{6 \omega L}\left(3 \theta-2 \alpha-\frac{\pi}{3}\right)
\end{aligned}
$$

I4: $i_{a}(\theta)=\frac{\sqrt{2} k}{2 L}[3 \cos (\alpha+\varphi)-\cos \varphi-2 \cos (\theta+\varphi)]-$

$$
-\frac{V_{d c}}{3 \omega L}\left(2 \theta-\frac{3 \alpha}{2}-\frac{\pi}{3}\right)
$$

$$
\begin{aligned}
I 5: i_{a}(\theta)=\frac{\sqrt{2} k}{2 L}[ & \left.3 \cos (\alpha+\varphi)-\sqrt{3} \cos \left(\theta+\varphi-\frac{\pi}{6}\right)\right]- \\
& -\frac{V_{d c}}{2 \omega L}(\theta-\alpha) \\
I 6: i_{a}(\theta)= & \frac{\sqrt{2} k}{L}[\cos (\alpha+\varphi)-\cos (\theta+\varphi)]- \\
- & \frac{V_{d c}}{3 \omega L}\left(\theta-\alpha+\frac{\pi}{3}\right)
\end{aligned}
$$
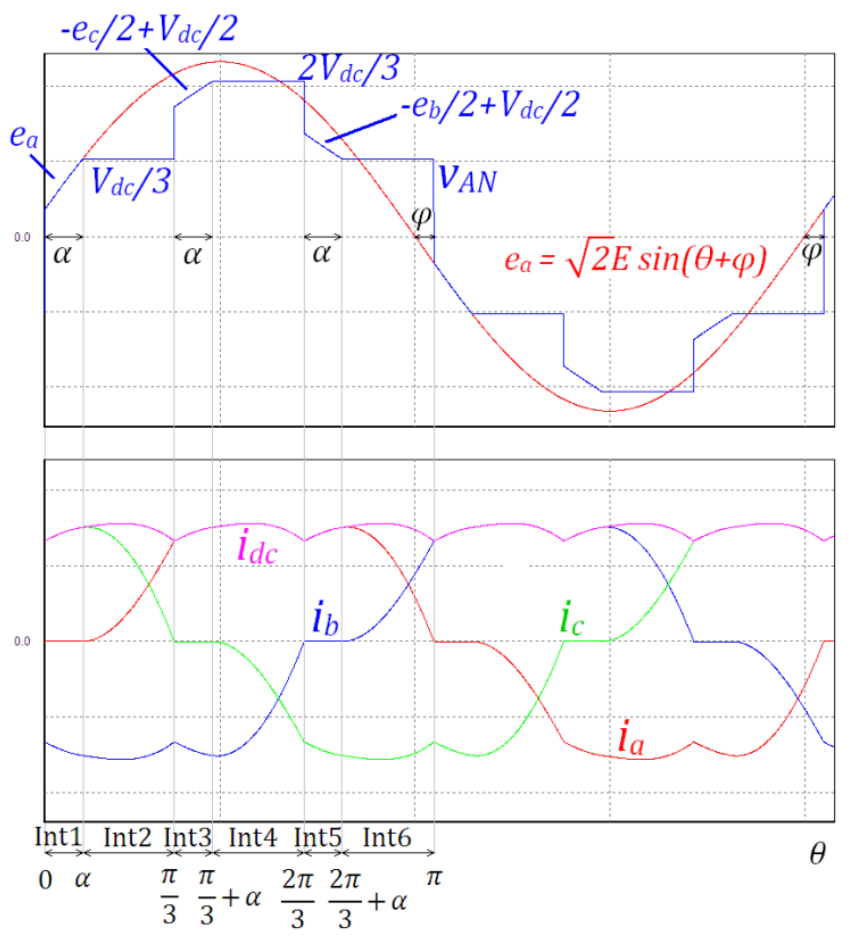

Figure 15. Waves for discontinuous conduction mode (DCM)
Then, thanks to the conditions $e_{a}(\theta=\alpha)=V_{d c} / 3$ and $i_{a}(\theta=\pi)=0$, the angles $\varphi$ and $\alpha$ can be calculated. Defining $\beta=\alpha+\varphi$, the first condition yields to:

$$
\beta=\alpha+\varphi=\sin ^{-1}\left(\frac{V_{d c}}{3 \sqrt{2} E}\right)
$$

From the second condition, (19) and (20):

$\frac{\sqrt{2} k}{L} \cos \varphi-\frac{V_{d c}}{3 \omega L} \varphi+\frac{\sqrt{2} k}{L} \cos \beta-\frac{V_{d c}}{3 \omega L}\left(\frac{4 \pi}{3}-\beta\right)=0$

The Newton-Raphson method is used to determine $\varphi$ from (21) and (20) is used to determine $\alpha$. Hence, on account of (14)-(21), the expressions of phase current $i_{a}$ is defined at any time as a function of the shaft speed $\omega_{m}$ and the capacitor voltage $V_{d c}$ at steady-state operation.

Making use of (12), the output power $P_{0}$ can be obtained. Considering the expression for the current $i_{a}$, an expression for the diode bridge output power $P_{0}\left(\omega_{m}, V_{d c}\right)$ in DCM is obtained as a function of the speed $\omega_{m}$ and the voltage $V_{d c}$ :

$$
\begin{gathered}
P_{0}=\frac{3 \sqrt{2} k \cdot V_{d c}}{2 \pi L}[\sin \varphi+\sin (\alpha+\varphi)+(\pi-\varphi) \cos (\alpha+\varphi)]- \\
-\frac{\sqrt{2} k \cdot V_{d c}}{2 L} \cos \varphi-\frac{V_{d c}^{2}}{\omega L}\left(\frac{2 \pi}{9}-\frac{\alpha}{2}-\frac{\alpha^{2}}{4 \pi}\right)
\end{gathered}
$$

\section{Boundary between Modes of Conduction}

The expressions for the power $P_{0}\left(\omega_{m}, V_{d c}\right)$ have been obtained for CCM and DCM. Now, in order to choose the corresponding expression, the mode of conduction must be known. For this purpose, an expression for the boundary between modes of conduction is obtained below.

As the angle $\varphi$ in Fig. 14 gets smaller, the voltage $e_{a}$ at $\theta=0$ decreases. The value of $e_{a}$ below which the diode D1 does not start conducting at $\theta=0$ represents the beginning of the discontinuous conduction mode. This value is given by:

$$
e_{a}(\theta=0)=\sqrt{2} E \sin \varphi=V_{d c} / 3
$$

With (23) and (11), a relationship between $V_{d c}$ and $E$ can be determined for the boundary between CCM and DCM:

$$
V_{d c}=\frac{9 \sqrt{2}}{\sqrt{4 \pi^{2}+9}} E
$$

The boundary between the DCM and the non-conduction mode (NCM) is defined by the following well-known relationship:

$$
V_{d c}=\sqrt{6} E
$$

\section{Simulation RESUlts}

The global system of Fig. 1, features shown in Table I and Table II, has been modeled using the software PSIM. The boost converter is replaced by a voltage controlled current source where the current is obtained according to the 
calculated optimum curve $I_{\text {Lcalc }}\left(V_{d c}\right)$. A real wind profile is applied to four different calculated curves previously described: $I_{\text {Lopt }}\left(V_{d c}\right), I_{L \omega \max }\left(V_{d c}\right), I_{L \omega \min }\left(V_{d c}\right)$ and $I_{L R=0}\left(V_{d c}\right)$. For the calculation of $I_{L o p t}\left(V_{d c}\right)$ and $I_{L R=0}\left(V_{d c}\right)$, all the parameters are perfectly known (apart from $R$, which is considered as 0 for $I_{L R=0}\left(V_{d c}\right)$ ), whilst for the calculation of $I_{L \omega \max }\left(V_{d c}\right)$ and $I_{L \omega m i n}\left(V_{d c}\right)$, realistic errors are considered for the parameter estimation. The results are shown in Fig. 16 for the wind speed $(\mathrm{m} / \mathrm{s})$, the different rotor speeds $(\mathrm{rpm})$ and captured powers $(\mathrm{W})$. The variables $\omega_{\text {mopt_dyn }}$ and $P_{\text {Topt dyn }}$ represent the actual optimum point, which could only be followed if there was no inertia. It can be observed how rotor speeds $\omega_{\text {mopt }}$, and $\omega_{m R=0}$ follow optimum speed $\omega_{m o p t} d y n$ with a small delay whereas rotor speeds $\omega_{\text {momax }}$ and $\omega_{\text {momin }}$ are always over and below optimum speed, respectively. As a result, captured power $P_{\text {Topt }}$ and $P_{T R=0}$ are very similar to optimum power $P_{\text {Topt_dyn }}$ while $P_{\text {Twmax }}$ and $P_{\text {Twmin }}$ are below optimum power.
More precisely, from the $45.95 \mathrm{Wh}$ which could have been obtained from second 10 to 120 , a $99.15 \%$ was captured with $I_{L o p t}\left(V_{d c}\right)$ curve, a $99.04 \%$ with $I_{L R=0}\left(V_{d c}\right)$ curve, a $79.96 \%$ with $I_{L \omega \max }\left(V_{d c}\right)$ curve, and a $58.08 \%$ with $I_{L \omega m i n}\left(V_{d c}\right)$ curve. These results confirm the predicted analysis: the resistance can be neglected for the optimum curve calculation and the performance of the MPPT can be drastically reduced due to errors in the parameters.

The MPPT efficiencies for the curves $I_{L o p t}\left(V_{d c}\right)$ and $I_{L R=0}\left(V_{d c}\right)$ are similar and very high, which confirms that the resistance can be neglected for the modeling. However, low MPPT efficiencies are obtained for the curves $I_{L \omega \max }\left(V_{d c}\right)$ and $I_{L \omega m i n}\left(V_{d c}\right)$. This means that, for the conventional curve-based MPPT method, an additional control should be added to compensate for the errors in case that accuracy in the parameters cannot be guaranteed.
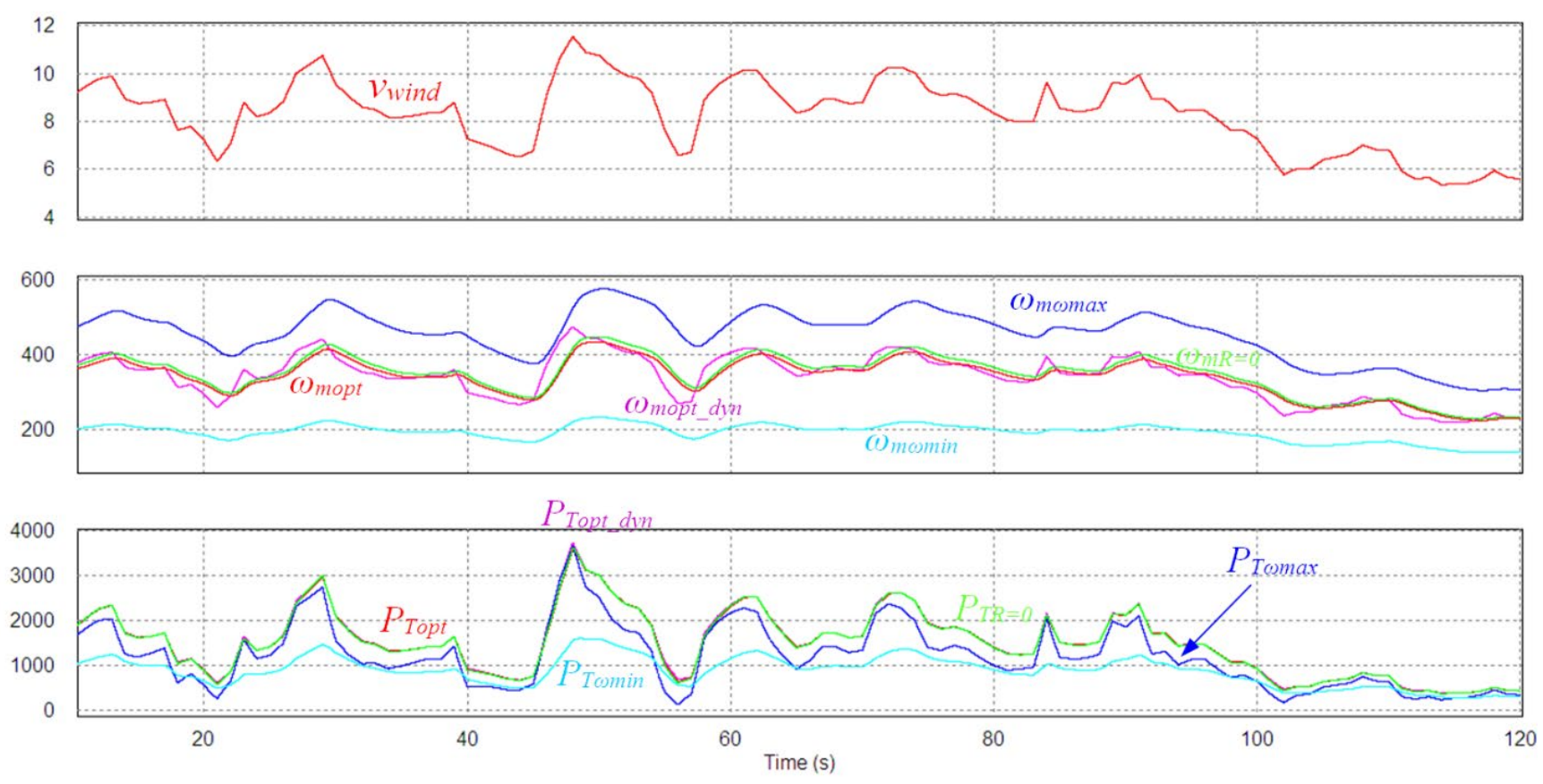

Figure 16. Simulation results

\section{CONCLUSION}

Using an accurate model, a robustness analysis of the conventional curve-based MPPT for a small WECS based on PMSG with diode bridge has been carried out. By means of two realistic scenarios of parameter variation, it is shown how the captured power can be significantly reduced. Thus, an additional control to compensate for the estimation errors is necessary in case that accuracy in the parameters cannot be guaranteed. On the other hand, it is proved that the resistance has no influence on the MPPT efficiency and can then be neglected, which leads to a much simpler model. The power curves for the PMSG with diode bridge with $R=0$ have thus been provided. Simulation results for an actual wind profile corroborate the theoretical analysis for all scenarios.

\section{REFERENCES}

[1] REN21 Renewable Energy Policy Network for the $21^{\text {st }}$ Century, "Renewables global status report 2013".

[2] AWEA American Wind Energy Association, "AWEA U.S. small wind turbine market report year ending 2011 ".

[3] J.A. Baroudi, V. Dinavahi, and A.M. Knight, "A review of power converter topologies for wind generators," IEEE International Conference on Electric Machines and Drives, pp. 458-465, May 2005.

[4] H. Wang, C. Nayar, J. Su, and M. Ding, "Control and interfacing of a grid-connected small-scale wind turbine generator," IEEE Transactions on Energy Conversion, vol. 26, no. 2, pp. 428-434, June 2011.

[5] M. Kesraoui, N. Korichi, and A. Belkadi, "Maximum power point tracker of wind energy conversion system," Renewable Energy, vol. 36 , no. 10 , pp. 2655-2662, October 2011. 
[6] E. Koutroulis, and K. Kalaitzakis, "Design of a maximum power tracking system for wind-energy-conversion applications," IEEE Transactions on Industrial Electronics, vol. 53, no. 2, pp. 486-494, April 2006.

[7] S.M.R. Kazmi, H. Goto, H.J. Guo, and O.Ichinokura, "A novel algorithm for fast and efficient speed-sensorless maximum power point tracking in wind energy conversion systems," IEEE Transactions on Industrial Electronics, vol. 58, no. 1, pp. 29-36, Jan. 2011.

[8] M. Narayana, G. A. Putrus, M. Jovanovic, P. S. Leung, and S. McDonald, "Generic maximum power point tracking controller for small-scale wind turbines," Renewable Energy, vol. 44, pp. 72-79, August 2012.

[9] Z. M. Dalala, Z. U. Zahid, W. Yu, Y. Cho, and J. S. Lai, "Design and analysis of an MPPT technique for small-scale wind energy conversion systems," IEEE Transactions on Energy Conversion, vol. 28, no. 3, pp. 756-767, September 2013.

[10] M. E. Haque, M. Negnevitsky, and K. M. Muttaqi, "A novel control strategy for a variable-speed wind turbine with a permanent-magnet synchronous generator," IEEE Transactions on Industry Applications, vol. 46, no. 1, pp. 331-339, January 2010.

[11] V. Lazarov, D. Roye, D. Spirov, and Z. Zarkov, "New control strategy for variable speed wind turbine with DC-DC converters," Power Electronics and Motion Control Conference, T12-120 - T12124, September 2010.

[12] Y. Zou, M. E. Elbuluk, and Y. Sozer, "Stability analysis of maximum power point tracking (MPPT) method in wind power systems," IEEE Transactions on Industry Applications, vol. 49, no. 3, pp. 1129-1136, May 2013.

[13] J. Chen, J. Chen, and C. Gong, "Constant-bandwidth maximum power point tracking strategy for variable-speed wind turbines and its design details," IEEE Transactions on Industrial Electronics, vol. 60, no. 11, pp. 5050-5058, November 2013.

[14] S. M. Dehghan, M. Mohamadian, and A. Y. Varjani, "A new variable-speed wind energy conversion system using permanentmagnet synchronous generator and Z-source inverter," IEEE Transactions on Energy Conversion, vol. 24, no. 3, pp. 714-724, September 2009.

[15] S. Song, S. Kang, and N. Hahm, "Implementation and control of grid connected AC-DC-AC power converter for variable speed wind energy conversion system," Applied Power Electronics Conference and Exposition, vol. 1, pp. 154-158, February 2003.

[16] I. Serban, and C. Marinescu, "A sensorless control method for variable-speed small wind turbines," Renewable Energy, vol. 43, pp. 256-266, July 2012.

[17] A. Urtasun, P. Sanchis, I. San Martín, J. López, and L. Marroyo, "Modeling of small wind turbines based on PMSG with diode bridge for sensorless maximum power tracking," Renewable energy, vol. 55, pp. 138-149, July 2013.

[18] M. Rizo, A. Rodríguez, E. Bueno, and F.J. Rodríguez, "Robustness analysis of wind turbines based on PMSG with sensorless vector control," Annual Conference on IEEE Industrial Electronics Society, pp. 3103-3108, November 2010.

[19] J. Chen, J. Chen, and C. Gong, "New overall power control strategy for variable-speed fixed-pitch wind turbines within the whole wind velocity range," IEEE Transaction on Industrial Electronics, vol. 60, no. 7, pp. 2652-2660, July 2013.

[20] P. Pejovic, and J. W. Kolar, "An analysis of three-phase rectifiers with constant voltage loads," Circuits and Systems for Communications, pp. 119-126, November 2010.

\section{BIOGRAPHIES}

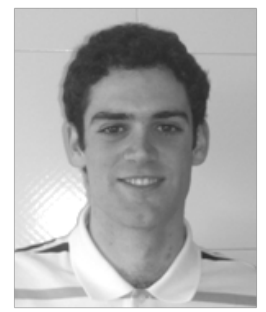

Andoni Urtasun (S'11) was born in Pamplona, Spain, in 1987. He received the M.Sc. degree in electrical engineering from the Public University of Navarre, Pamplona, Spain, and from the Institut National Polytechnique de Toulouse, Toulouse, France, both in 2010.

In 2010, he joined the Electrical Engineering, Power Electronics and Renewable Energy research group, Public University of Navarre, where he is currently pursuing his Ph.D. His research interests include power electronics and hybrid renewable energy systems.

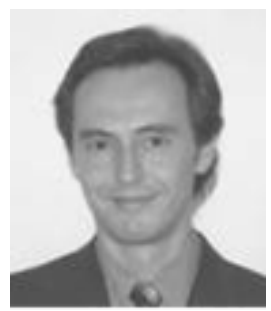

Pablo Sanchis (M'03-SM'12) received the M.Sc. and Ph.D. degrees in electrical engineering in 1995 and 2002, respectively, and the M.Sc. degree in management and business administration in 1994, all from the Public University of Navarra, Pamplona, Spain.

From 1996 to 1998, he worked as a Guest Researcher at Delft University of Technology, The Netherlands, on the field of control of electric machines. In 1998, he joined the Department of Electrical and Electronic Engineering at the Public University of Navarra, Spain, where he is currently Associate Professor. He is also Director of the Renewable Energies Space and Vice Dean of the College of Engineering of this university.

Dr. Sanchis is member of the IEEE, the IET, the CIGRE and the Spanish Hydrogen Association (AEH2). He has been involved in many research projects mainly in co-operation with industry. His research interests include renewable energies, power electronics, hydrogen technologies, electric grid integration and electric microgrids.

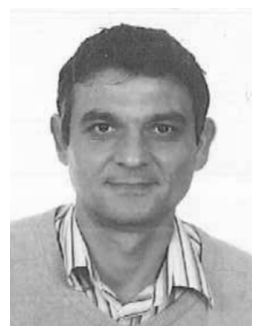

Luis Marroyo (M'04) received the M.Sc. degree in electrical engineering in 1993 from the University of Toulouse, France, and the Ph.D. degree in electrical engineering in 1997 from the UPNA, Spain, and in 1999 from the LEEIENSEEIHT INP Toulouse, France. From 1993 to 1998, he was Assistant Professor at the Department of Electrical and Electronic Engineering of the UPNA, where he currently works as Associate Professor, since 1998. He is the head of the INGEPER research group. He has been involved in more than 60 research projects mainly, in co-operation with industry, he is the co-inventor of 11 international patents and coauthored of more than 70 papers in international journals and conferences. His research interests include power electronics, grid quality and renewable energy. 